International Journal of Enginering \& Technology, $7(4.34)(2018)$ 340-347
WPC
Website: www.sciencepubco.com/index.php/IJT
Research pa

\title{
The Influence of Business Environment and Capabilities on Transient Competitive Advantage and Their implications for Business Performance of Micro, Small and Medium Enterprises in Indonesia
}

\author{
Nurul Hermina*, Adjeng Mariana, Keni Kaniawati \\ Fakultas Bisnis Manajemen Universitas Widyatama Indonesia \\ *Corresponding author E-mail: hermina.nurul@gmail.com
}

\begin{abstract}
Micro, small and medium enterprises (MSME - Indonesian: UMKM - Usaha Micro, Kecil dan Menengah) are the key to increase growth, create employment, act as the source of people's income, to fulfil the need of goods and services, to increase the added values which eventually influence the economic growth. This research is aimed to explain how business environment and capability influence the competitive advantage which plays an important role that determines the business performance of MSME. The total sample able to be collected with web-based design is $56 \mathrm{MSME/UMKM} \mathrm{from} \mathrm{all} \mathrm{over} \mathrm{Indonesia.} \mathrm{The} \mathrm{analysis} \mathrm{technique} \mathrm{used} \mathrm{is} \mathrm{structural} \mathrm{equation} \mathrm{model-}$ ing (SEM). The study proves that business environment does not significantly influence the business performance of MSME/UMKM. However, this variable contributes significant indirect influence with a greater level than its direct influence. The finding indicates that improvement in business environment will be able to boost the business performance if it is combined with the improvement in competitive advantage of the MSME/UMKM.
\end{abstract}

Keywords: Transient competitive advantage; Business Performance; SEM; UMKM/MSME; Web-based Sampling.

\section{Introduction}

Competitive advantage shall determine the economic productivity level of a country and a high level of productivity reflects high level of competitiveness; while high level of competitiveness has the potential to encourage high level of economic growth that eventually shall increase the level of people's welfare [1]. In order to materialize the potentials, the Indonesian government has identified micro, small, and medium enterprises (MSME - Indonesian: Usaha Mikro Kecil, Menengah - UMKM) as the key to increase growth, to create employment, to act as the source of people's income, to supply the need of goods and services, and as an added value that may result in an increase of economic growth [2]. Currently, MSME play an important role in Indonesian economy, that can be observed from: their contribution towards the Gross Domestic Product (GDP) which is $61.41 \%$, the number of MSME which raised from $1.67 \%$ to $3.1 \%$ in early 2017 , their contribution towards the economy growth which reached up to $99 \%$, and their contribution towards employment which absorbed $96.71 \%$ of labor force [3]. However, at the global competition level, the level of competitiveness of Indonesia still ranked 43th out of 63 countries, in which the factors that become the measurements of competitiveness cover: macro economy, business efficiency, technology-based business, and innovation (IMD world competitiveness yearbook 2018). Although the ratio of self-employment, increased from $1.67 \%$ to $3.1 \%$, it was still lower than other ASEAN members (Badan Pusat Statistik). The contribution indicator of MSME towards the GDP showed an increase. However, the access of MSME to the global supply chain was very minimum, i.e. $0.8 \%$
(Ikatan Sarjana Ekonomi Indonesia - The Association of Indonesian Economists). Based on the identification of secondary data obtained from experts in economy, it can be determined that there are some obstacles to developing MSME in Indonesia which cover: inability to accommodate the development of macro economy indicators, lack of technology application, the change of global market, capital, lack of knowledge about marketing strategy related to branding, insufficient promotion, problem in setting up the market segment, low quality products resulted, limitation in human resources and their quality, and lack of innovation.

To build continuous competitive advantage, business practitioners are required to have the capability to immediately respond to changes in their environment [4], to improve their ability to stay competitive and to survive in a very competitive environment to vary products, to adapt and, further, to reorganize to adjust to the development of market condition and technology to survive and succeed [5-6]. A study conducted by [7] involving 86 executives of companies in food industry in Iran showed that there was a relationship between environment uncertainty with competitive advantage and business performance; while research done by $\mathrm{Wu}$ (2010) on 253 companies in Taiwan indicated that there was a relationship between environment turbulence, dynamic capability, and competitive advantage. Another research related to the environment of an industry which was conducted by [8] on 62 banks in Kenya, confirmed that there was a positive and strong connection between business attraction and business performance.

The Indonesian government has worked hard to improve the business performance of MSME. However, in reality, based on the current condition, conceptual analysis and the result of previous research, it can be concluded that the business performance of 
MSME has not yet achieved a satisfactory level. It is assumed that MSME have not been able to respond and adjust to dynamic business environment and to improve their business capability optimally, so that they are not yet able to create competitive advantage which eventually influence their business performance.

This research is aimed to investigate how business environment and capability influence the transient competitive advantage and their implications for business performance of MSME in Indonesia.

\section{Theoretical and methodology framework}

In [9] stated that to keep pace with a turbulent environment, companies have to continuously reconfigure their internal resources and capability to maintain continuity of their competitive advantage and to achieve excellent business performance. According to [10], there are six factors of macro environment which need immediate responses from companies, i.e.: economy, demography, social, technology, politics and law, and globalization. The strength of industry environment needs to be taken into account by companies too, which is in line with [11] who stated that the first thing which triggers profitability is whether or not companies are in an attractive industry that can be seen from 5 strengths of Porter's. Further, according to them, companies should find out their position of competitive advantage within the industry from the view point of cost and revenue, compared to their competitors.

In setting up competitive advantage, besides responding to their business environment, companies have to adjust their capability to the need of their business environment as stated by [12]. According to them, company capability is an ability to evaluate resources and capability based on company's business functions which cover: marketing, finance, research and development, human resources, and information system.

In [13] stated that companies are considered to have competitive advantage if they are able to perform above average or continuously gain profit above normal rent. Completing [14] stated that companies are demanded to be more competitive with transient competitive advantage than continuous competitive advantage as the later shall erode along with uncertain and unstable environment change; and therefore, determining the strategies must be based on transient competitive advantage, by exploiting short term opportunities fast and dynamically reallocating resources to all of the organisation elements, building innovation excellence, and creating effective company leadership pattern and mind set.

Company's competitive advantage will influence business performance. According to [15], a good company must have a comprehensive and systematic performance measurement system with four measurement perspectives, i.e.: financial, customer, internal business process, and learning and growth perspectives.

\section{Methodology}

This research is intended to study the influence of business environment and capability on transient competitive advantage and their implications for business performance of Micro, Small, and Medium Enterprises (MSME). The performance of MSME is the output or result of the implementation of all activities related to business operation supported by the right transient competitive advantage The research methodology is using the approach from Management Economics focusing on the Management Strategy with the understanding level of management on business environment, capability, transient competitive advantage, and business performance Hence, based on the aim of this research which is to obtain a description of variables being studied and to find out the connection among variables, this research is a descriptive and verificative.

\subsection{Research Hypothesis}

This research is to test the hypothesis of the influence of Business Environment (BE) and Capability (C) over the Transient Competitive Advantage (TCA) and the implications for the business Performance $(\mathrm{P})$ of MSME.

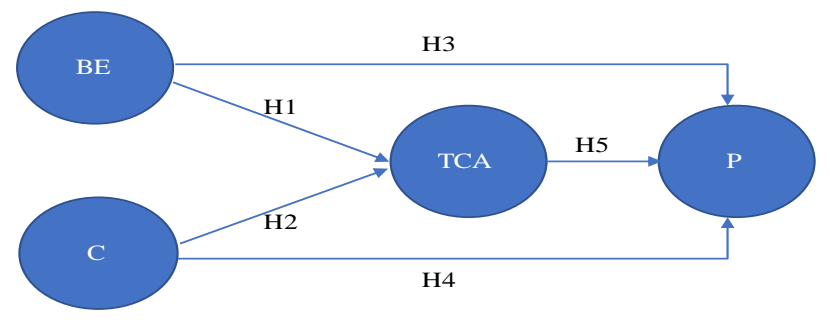

Fig. 1: Research Paradigm

where

BE: Business Environment

C: Capability

TCA: Transient Competitive Advantage

B: Business Performance of MSME

\subsection{Population and Sample}

The population of this research is MSME throughout Indonesia. The total sample collected for this research is 56 of MSME. Sample collection is done through website.

\subsection{Research Variables}

There are four variables used in this research. Each variable consists of several indicators.

Table 1: Research Variable Operation

\begin{tabular}{|l|c|}
\hline \multicolumn{1}{|c|}{ Variable } & Number of Indicators \\
\hline Business Environment & 48 \\
\hline Capability & 21 \\
\hline Transient Competitive Advantage & 10 \\
\hline Business Performance & 10 \\
\hline
\end{tabular}

\subsection{Data Analysis Technique}

he data analysis technique used to test the hypotheses is Structural Equation Modelling (SEM) technique; the technique which is used to find out the connectivity pattern among variables, whether or not there is direct or indirect influence of some independent variables (exogenous) towards dependent variables (endogenous variables).

The reason why SEM data analysis technique is used is that besides the fact that the aim of the research is to figure out the influence of exogenous variables towards the endogenous variable, the variables involved are latent variables, i.e.: variables which cannot be measured directly but must be measured using dimensions and indicators. The influence among variables which will be tested is built on a particular theoretical framework, which is able to explain the quality of the connectivity among the variables [16].

SEM analysis is used to test the connectivity model among variables in a form of cause-effect (causing-modelling). Therefore, in the connectivity model among variables there are independent variables (free) and dependent variables (bound).

SEM analysis technique used in this research is Partial Least Square Path Modelling (PLS-PM) because the sample is less than 200. The main purpose of using PLS is to predict. Other than predicting, PLS is also used to confirm a theory and verify whether or not there is a connection among the latent variables. The focus of PLS is to maximize the variance of dependent variables verified by the independent variables as a substitute to produce covariance empirical matrix.

The model which will be estimated in this study is as under: 
$\eta_{1}=\gamma_{11} \xi_{1}+\gamma_{12} \xi_{2}+\zeta_{1}$

$\eta_{2}=\gamma_{21} \xi_{1}+\gamma_{22} \xi_{2}+\beta_{21} \eta_{1}+\zeta_{1}$

where

$\eta_{2}$ : Business Performance of MSME

$\eta_{1}$ : Transient Competitive Advantage

$\xi_{1}$ : Business Environment

$\xi_{2}:$ Capability

$\zeta_{1}, \zeta_{2}:$ Model Error

PLS-PM consists of two models, i.e.: measurement model and structural model. Measurement model analysis covers validity analysis and reliability analysis.

\subsection{Validity Analysis}

Validity analysis is correlation analysis between items and dimension. Validity coefficient greater than 0.500 determines that the indicator is valid [16]. Validity coefficient is measured with the following formula:

$$
\operatorname{Cor}^{2}\left(x_{j h} \xi_{j}\right)=\frac{n \sum_{i=1}^{n} x_{i j h} \xi_{i j}-\sum_{i=1}^{n} x_{i j h} \sum_{i=1}^{n} \xi_{i j}}{\sqrt{\left[n \sum_{i=1}^{n} x_{i j h}^{2}-\left(\sum_{i=1}^{n} x_{i j h}\right)^{2}\right]\left[n \sum_{i=1}^{n} \xi_{i j}^{2}-\left(\sum_{i=1}^{n} \xi_{i j}\right)^{2}\right]}}
$$

where

$\mathrm{x}_{\mathrm{jh}}$ : the $\mathrm{h}^{\text {th }}$ item of the $\mathrm{jth}$ dimension

$\xi_{\mathrm{j}}$ : the $\mathrm{j}^{\text {th }}$ dimension

\subsection{Reliability Analysis}

The most common reliability analysis used is composite reliability (CR) and Average Extracted Variance (AVE)

\subsubsection{Composite Reliability}

Composite Reliability is formulated as under:

$\mathrm{CR}=\left(\Sigma_{j} l_{\mathrm{j}}\right)^{2} /\left[\left(\sum_{j} l_{\mathrm{j}}\right)^{2}+\left(\sum_{j}\left(1-l_{j}^{2}\right)\right]\right.$

where

$C R$ : Coefficient Composite Reliability

$J$ : the number of indicators

$l_{\mathrm{k}}$ : Standardized loading factor

\subsubsection{Average Extracted Variance}

AVE is formulated as the following:

$\mathrm{AVE}=\Sigma_{j} l_{\mathrm{j}}^{2} / J$

A questionnaire is considered to have good reliability if the value of $\mathrm{CR}$ is greater or equal to 0.700 and AVE > 0.500 [16].

\subsection{Structural Model}

Structural model is a regression model for latent variable. Regression coefficient is obtained by using ordinary least square (OLS) method:

$\beta=\left(\xi^{\mathrm{t}} \xi\right)^{-1} \xi^{\mathrm{t}} \eta$

where

$\beta$ : Coefficient of the influence of exogenous variable towards the endogenous variable

$\xi$ : Exogenous variable

$\eta$ : Endogenous variable

\subsection{Goodness of fit index}

Goodness of fit index is a descriptive measurement used in PLS to evaluate the quality of the models made. There are four evaluation measurements.

\section{Results of Analysis}

\subsection{Demography}

Table 2: Respondent Demography

\begin{tabular}{|c|c|c|c|}
\hline \multicolumn{2}{|c|}{ Information } & Frequency & $(\%)$ \\
\hline Turn over growth & Less than one year & 1 & 1.79 \\
\hline & Below 10\% & 4 & 7.14 \\
\hline & 10 up to 30\% & 47 & 83.93 \\
\hline & Above 30\% & 4 & 7.14 \\
\hline Education & Bachelor's Degree & 33 & 58.93 \\
\hline & Master's Degree & 20 & 35.71 \\
\hline & Doctorate's Degree & 3 & 5.36 \\
\hline & Owner & 40 & 71.43 \\
\hline Position & Manager & 9 & 16.07 \\
\hline & General Manager & 2 & 3.57 \\
\hline & Senior Manager & 5 & 8.93 \\
\hline
\end{tabular}

The result of analysis indicates that the majority of MSME has a turnover at the percentage of 10 to $30 \%$. Respondents' education is Bachelor's Degree and the position is the owner of MSME.

\subsection{Modeling}

Business environment and capability are hypothesized as giving positive and significant influence on the competitive strategy and providing positive impact towards the business performance of MSME. Further, SEM is implemented to prove the hypothesis. Structural equation modelling of the influence of business environment and capability towards the transient competitive strategy and their implications for MSME business performance is carried out. SEM applied in this study is a model which is based on variance structure because the sample available is less than 100 units. Structural modelling has two analysis phases namely measurement model analysis and structural model analysis. Measurement model analysis is related to validity analysis and indicator reliability used to measure dimension or research variable; while structural model analysis explains the influence of competitive strategy towards the business performance of MSME in Indonesia. Measurement analysis in this study involves second order model; dimension as the first order and research variable as the second order.

Prior to this, analysis on the suitability of the model constructed and the data collected is carried out using Goodness of Fit Index. The result of GoF calculation provides a value of 0.536 . Another measurement used is predictability Q2 $=1-(1-\mathrm{R} 12)(1-\mathrm{R} 22)$. The analysis result indicates a determination coefficient of the model constructed 0.240 and 0.410 . Therefore, the value of $\mathrm{Q} 2=1-(1-$ $0.240)=0.552$. The value of GoF and Q2 obtained is greater than 0.500 , which means the ability to explain the research phenomena is greater than $50 \%$. It means the model is good enough to explain the phenomena being studied.

4.2.1. Measurement Model Analysis

Measurement model analysis is conducted to find out the indicator validity and reliability in measuring the dimension and the dimension in measuring the research variable. Indicator and dimension are considered valid if the value of loading factor (validity coefficient) is greater than 0.500 and considered reliable if the value of Composite Reliability (CR) is greater than 0.700 and the value of AVE is greater than 0.500 . This analysis is also used to figure out the most important item and dimension needed to measure the research variable, so that they can be used as a reference to make improvements to company's business performance.

The first variable of this study is business environment variable. Business environment variable is theoretically constructed by external environment and industry environment variables. 
Table 3: Validity and Reliability Analysis of First Order Indicator of External Environment Variable $\mathrm{R}^{2}$

\begin{tabular}{|c|c|c|c|c|c|c|}
\hline Item & & Average & Loading Factor & $\mathrm{R}^{2}$ & Variance Error & t-Value \\
\hline Political Stability & A1.1 & 3.411 & 0.850 & 0.723 & 0.278 & 14.680 \\
\hline Tax Regulation & A1.2 & 3.357 & 0.849 & 0.721 & 0.279 & 20.885 \\
\hline Regulation for Foreign Trade & A1.3 & 3.107 & 0.745 & 0.555 & 0.445 & 7.850 \\
\hline Welfare Policy & A1.4 & 3.089 & 0.714 & 0.510 & 0.490 & 7.460 \\
\hline Trend of Gross Domestic Income & A2.1 & 3.643 & 0.656 & 0.430 & 0.570 & 8.333 \\
\hline Inflation Rate & $\mathrm{A} 2.2$ & 3.464 & 0.756 & 0.572 & 0.428 & 10.403 \\
\hline Interest Level & A2.3 & 3.286 & 0.680 & 0.462 & 0.538 & 6.880 \\
\hline Payroll Regulation & $\mathrm{A} 2.5$ & 3.357 & 0.629 & 0.396 & 0.604 & 5.210 \\
\hline Foreign currency market & A2.6 & 3.286 & 0.764 & 0.584 & 0.416 & 10.402 \\
\hline Unemployment level & A2.7 & 3.321 & 0.720 & 0.518 & 0.482 & 11.127 \\
\hline Changes in life style & A3.1 & 3.732 & 0.708 & 0.501 & 0.499 & 9.699 \\
\hline Consumers' activity tendency to be consumptive & $\mathrm{A} 3.2$ & 3.661 & 0.713 & 0.508 & 0.492 & 8.269 \\
\hline Population growth & A3.3 & 3.464 & 0.709 & 0.503 & 0.497 & 11.144 \\
\hline Education level & $\mathrm{A} 3.4$ & 3.357 & 0.720 & 0.518 & 0.482 & 11.997 \\
\hline Social Mobility & A3.5 & 3.446 & 0.721 & 0.520 & 0.480 & 9.580 \\
\hline Income distribution & A3.7 & 3.375 & 0.514 & 0.264 & 0.736 & 3.610 \\
\hline $\begin{array}{l}\text { New technology( Internet, Digital Technology, Financial technology, } \\
\text { Big Data) }\end{array}$ & A4.1 & 4.107 & 0.808 & 0.653 & 0.347 & 19.565 \\
\hline Government's focus on industry in terms of technology & A4 2 & 3.357 & 0.826 & 0.682 & 0.318 & 16.210 \\
\hline Government expenses for research & A4 3 & 2.714 & 0.787 & 0.619 & 0.381 & 12.874 \\
\hline Speed of technology transfer & A4 4.4 & 3.554 & 0.863 & 0.745 & 0.255 & 26.422 \\
\hline Effort to maintain environment & A5.1 & 2.946 & 0.799 & 0.638 & 0.362 & 12.657 \\
\hline Environment preservation program (Green building, green product) & A5.2 & 2.821 & 0.776 & 0.602 & 0.398 & 9.469 \\
\hline Impact of climate change towards company & A5.3 & 3.125 & 0.684 & 0.468 & 0.532 & 8.950 \\
\hline Speed of technology transfer & A5.4 & 3.429 & 0.669 & 0.448 & 0.552 & 7.998 \\
\hline Impact of environment damage and natural disaster & A5.5 & 3.179 & 0.758 & 0.575 & 0.425 & 11.183 \\
\hline Availability/limitation of raw materials & A5.6 & 3.429 & 0.541 & 0.293 & 0.707 & 3.629 \\
\hline Legitimation of company monopoly & A6.1 & 3.286 & 0.758 & 0.575 & 0.425 & 14.538 \\
\hline Labor law & A6.2 & 3.125 & 0.812 & 0.659 & 0.341 & 14.816 \\
\hline Health and Safety & A6.3 & 3.196 & 0.824 & 0.679 & 0.321 & 12.716 \\
\hline Product Safety & A6.4 & 3.375 & 0.775 & 0.601 & 0.399 & 11.003 \\
\hline
\end{tabular}

It can be observed from the above table that all indicators of external environment variable have a loading factor greater than 0.500 , and the value of composite reliability and average variance extracted greater than 0.500 . The result confirms that the indicators used to measure external environment variable is valid and reliable.

Table 4: Validity and Reliability Analysis of the First Order Indicator of Industry Environment Variable

\begin{tabular}{|c|c|c|c|c|c|c|}
\hline \multicolumn{2}{|l|}{ Item } & Average & Loading Factor & $\mathrm{R}^{2}$ & Variance Error & t-Value \\
\hline $\begin{array}{l}\text { Product differentiation, i.e. : product and service delivered by current } \\
\text { business practitioners to buyers which are different from one another }\end{array}$ & B1.1 & 3.411 & 0.767 & 0.588 & 0.412 & 15.717 \\
\hline $\begin{array}{l}\text { Economy scale or easiness level for candidates of future new comer } \\
\text { company to produce products in big quantity with more competitive } \\
\text { price than existing companies having experience in the industry }\end{array}$ & B1.2 & 3.607 & 0.775 & 0.601 & 0.399 & 10.463 \\
\hline $\begin{array}{l}\text { The implementation of the regulation related to the level of easiness to } \\
\text { future new comer companies who will enter the industry }\end{array}$ & B1.3 & 3.464 & 0.816 & 0.666 & 0.334 & 21.140 \\
\hline Required capital for new comers in industry & B1.4 & 3.304 & 0.782 & 0.612 & 0.388 & 13.272 \\
\hline The number of supply industry & B2.1 & 3.518 & 0.565 & 0.319 & 0.681 & 4.345 \\
\hline The cost of supplier transfer & B2.2 & 3.304 & 0.851 & 0.724 & 0.276 & 16.740 \\
\hline Supplier become competitor & B2.3 & 3.536 & 0.802 & 0.643 & 0.357 & 11.543 \\
\hline Substitute product of supplier & B2.4 & 3.393 & 0.820 & 0.672 & 0.328 & 16.465 \\
\hline The cost of customers transfer & B3.1 & 3.196 & 0.806 & 0.650 & 0.350 & 4.400 \\
\hline Purchase volume & B3.2 & 3.446 & 0.874 & 0.764 & 0.236 & 5.862 \\
\hline Number of competitor & B4.1 & 3.911 & 0.816 & 0.666 & 0.334 & 15.619 \\
\hline Industrial growth & B4.2 & 3.625 & 0.839 & 0.704 & 0.296 & 21.244 \\
\hline Competition intensity & B4.4 & 3.946 & 0.908 & 0.824 & 0.176 & 45.400 \\
\hline Price war intensity & B4.5 & 3.964 & 0.777 & 0.604 & 0.396 & 9.170 \\
\hline Competitors' strength & B4.6 & 3.875 & 0.856 & 0.733 & 0.267 & 18.240 \\
\hline \multicolumn{3}{|l|}{ Composite Reliability } & \multicolumn{4}{|c|}{0.966} \\
\hline \multicolumn{3}{|l|}{ Average Variance Extracted } & \multicolumn{4}{|c|}{0.641} \\
\hline
\end{tabular}

From the table above, it can be seen that all indicators of industry environment variable indicate a loading factor greater than 0.500 and the value of composite reliability and average variance extracted greater than 0.500 . The result confirms that the indicators used to measure industry environment variable are valid and reliable. Based on the analysis of external and industry environment variables, it can be concluded that business environment variable is measured by the indicators which are also valid and reliable. Further, the following table provides the result analysis of capability variable. 
Table 5: Validity and Reliability Analysis of First Order Indicator of Capability Variable

\begin{tabular}{|c|c|c|c|c|c|c|}
\hline \multicolumn{2}{|l|}{ Item } & Average & Loading Factor & $\mathrm{R}^{2}$ & Variance Error & t-Value \\
\hline Balance between stability and innovation & $\mathrm{C} 1.1$ & 3.661 & 0.796 & 0.634 & 0.366 & 16.736 \\
\hline Flexibility & $\mathrm{C} 1.2$ & 3.804 & 0.879 & 0.773 & 0.227 & 30.772 \\
\hline Focus on market exploration & $\mathrm{C} 1.3$ & 3.589 & 0.794 & 0.630 & 0.370 & 15.182 \\
\hline Bureaucracy & $\mathrm{C} 1.4$ & 2.982 & - & - & - & - \\
\hline Innovation culture & $\mathrm{C} 1.5$ & 3.589 & - & - & - & - \\
\hline Resources managed by central management & $\mathrm{C} 2.1$ & 3.196 & 0.680 & 0.462 & 0.538 & 7.407 \\
\hline Management focusing on searching business opportunity to grow & $\mathrm{C} 2.2$ & 3.643 & 0.705 & 0.497 & 0.503 & 8.324 \\
\hline To make access to assets rather than buying assets & $\mathrm{C} 2.4$ & 3.304 & 0.624 & 0.389 & 0.611 & 4.984 \\
\hline Resources efficiency in all organization elements & $\mathrm{C} 2.5$ & 3.714 & 0.724 & 0.524 & 0.476 & 10.169 \\
\hline Make use of external resources & $\mathrm{C} 2.6$ & 3.196 & 0.533 & 0.284 & 0.716 & 3.481 \\
\hline $\begin{array}{l}\text { Set up assessment (evaluation) on the current condition and decide } \\
\text { gap of growth }\end{array}$ & $\mathrm{C} 3.1$ & 3.464 & 0.711 & 0.506 & 0.494 & 10.365 \\
\hline Create senior management harmony and commitment to innovation & $\mathrm{C} 3.2$ & 3.429 & 0.753 & 0.567 & 0.433 & 10.417 \\
\hline Prepare the process of innovation management & $\mathrm{C} 3.3$ & 3.500 & 0.751 & 0.564 & 0.436 & 10.054 \\
\hline $\begin{array}{l}\text { Building supporting structure to innovate in order to exploit as much } \\
\text { profit as possible for the company }\end{array}$ & $\mathrm{C} 3.5$ & 3.518 & 0.731 & 0.534 & 0.466 & 11.426 \\
\hline $\begin{array}{l}\text { To listen, understand and respond information which is difficult to } \\
\text { accept in tight competition }\end{array}$ & $\mathrm{C} 4.1$ & 3.589 & 0.821 & 0.674 & 0.326 & 24.047 \\
\hline Responsive & $\mathrm{C} 4.2$ & 3.821 & 0.885 & 0.783 & 0.217 & 31.607 \\
\hline Risk taking & $\mathrm{C} 4.3$ & 3.625 & 0.575 & 0.331 & 0.669 & 4.139 \\
\hline Trying new things for learning & $\mathrm{C} 4.4$ & 3.732 & 0.742 & 0.551 & 0.449 & 9.104 \\
\hline Knowledge sharing to the organization & $\mathrm{C} 4.5$ & 3.964 & 0.827 & 0.684 & 0.316 & 17.016 \\
\hline \multicolumn{3}{|l|}{ Composite Reliability } & \multicolumn{4}{|c|}{0.958} \\
\hline \multicolumn{3}{|l|}{ Average Variance Extracted } & \multicolumn{4}{|c|}{0.552} \\
\hline
\end{tabular}

The analysis indicates that two indicators are not valid as the loading factor value is less 0.500 . The two items are decided to be expelled from the measurement capability model. After the two items are taken out, all other indicators have a loading factor value greater than 0.500 and the composite reliability and average variance extracted values greater than the minimum. The result confirms that all indicators are valid and reliable.

Table 6: Validity and Reliability Analysis of First Order Indicator of Competitive Advantage Variable

\begin{tabular}{|c|c|c|c|c|c|c|}
\hline \multicolumn{2}{|l|}{ Item } & Average & Loading Factor & $\mathrm{R}^{2}$ & Variance Error & t-Value \\
\hline Setting up price of service & D1.1 & 3.304 & 0.791 & 0.626 & 0.374 & 9.810 \\
\hline Formulation of promotion program of company & D1.2 & 3.464 & 0.852 & 0.726 & 0.274 & 21.692 \\
\hline Setting up product quality of company & D1.3 & 3.607 & 0.795 & 0.632 & 0.368 & 15.164 \\
\hline Cash flow management (Money availability) & D2.1 & 2.839 & 0.942 & 0.887 & 0.113 & 60.321 \\
\hline Management of operational cost control & D2.2 & 3.071 & 0.926 & 0.857 & 0.143 & 40.043 \\
\hline Understanding to do financial analysis of company & D2.3 & 2.804 & 0.931 & 0.867 & 0.133 & 46.734 \\
\hline Providing human resources & D3.1 & 3.071 & 0.842 & 0.709 & 0.291 & 20.071 \\
\hline Personnel development & D3.3 & 2.857 & 0.932 & 0.869 & 0.131 & 60.194 \\
\hline Personnel training & D3.4 & 2.875 & 0.863 & 0.745 & 0.255 & 18.501 \\
\hline \multicolumn{3}{|l|}{ Composite Reliability } & \multicolumn{4}{|c|}{0.971} \\
\hline \multicolumn{3}{|l|}{ Average Variance Extracted } & \multicolumn{4}{|c|}{0.773} \\
\hline
\end{tabular}

Transient competitive advantage shows that all indicators have a loading factor value or reliability coefficient greater than 0.500 and reliability value based on composite reliability and average variance extracted which can be categorized high. Based on the result, it can be concluded that all the indicators are valid and reliable. Further, validity and reliability analysis for business performance variable of MSME is carried out.

Table 7: Validity and Reliability Analysis of the First Order Indicator of Business Performance Variable

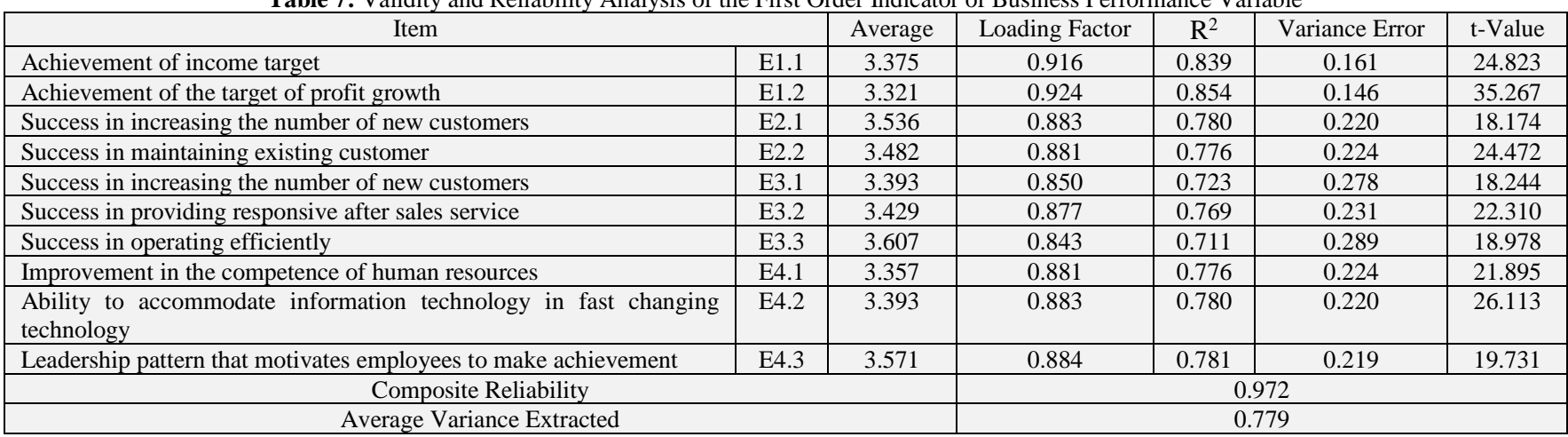


The result of the validity and reliability analysis of the business performance of MSME also shows that all indicators are valid and reliable. Therefore, it can be derived that all indicators for first order measurement model can be pronounced valid and reliable.

The second order measurement is further conducted as follows.

Table 8: Validity and Reliability Analysis of Second Order Variable of External Environment Variable

\begin{tabular}{|c|c|c|c|c|c|c|}
\hline \multicolumn{2}{|c|}{ Dimension } & Average & Loading Factor & $\mathrm{R}^{2}$ & Variance Error & $\mathrm{t}$-Value \\
\hline Political condition & LE1 & 3.241 & 0.680 & 0.463 & 0.537 & 8.235 \\
\hline Economy condition & LE2 & 3.393 & 0.864 & 0.746 & 0.254 & 19.022 \\
\hline Cultural and social condition & LE3 & 3.482 & 0.762 & 0.581 & 0.419 & 13.282 \\
\hline Technology condition & LE4 & 3.433 & 0.798 & 0.637 & 0.363 & 17.390 \\
\hline Ecology condition & LE5 & 3.155 & 0.748 & 0.560 & 0.440 & 11.426 \\
\hline Legal condition & LE6 & 3.246 & 0.843 & 0.711 & 0.289 & 19.564 \\
\hline \multicolumn{2}{|l|}{ Composite Reliability } & \multicolumn{3}{|c|}{0.868} \\
\hline
\end{tabular}

All dimensions of external environment variable of MSME possess a loading factor greater than 0.500 and also composite reliability and average variance extracted values greater that the minimum 0.700 and 0.600 . Such indicates that all dimensions of external environment variable of MSME are valid and reliable. The most important dimension is the economy condition with the greatest loading factor value. Nevertheless, this dimension shows achievement average value which is relatively low. Therefore, it should become the focus of attention to make improvements on the external environment of MSME.

Table 9: Validity and Reliability Analysis of Second Order Variable of Industry Environment Variable

\begin{tabular}{|c|c|c|c|c|c|c|}
\hline \multicolumn{2}{|c|}{ Dimension } & Average & Loading Factor & $\mathrm{R}^{2}$ & Variance Error & $\mathrm{t}$-Value \\
\hline Threats from new comers in MSME & LI1 & 3.446 & 0.717 & 0.514 & 0.486 & 9.954 \\
\hline Bargaining power of supplier to MSME & LI2 & 3.438 & 0.701 & 0.491 & 0.509 & 8.364 \\
\hline Bargaining pore of buyers & LI3 & 3.321 & 0.564 & 0.318 & 0.682 & 5.028 \\
\hline Intensity of industry competition & LI4 & 3.818 & 0.891 & 0.794 & 0.206 & 31.157 \\
\hline Composite Reliability & & \multicolumn{5}{|c|}{0.814} \\
\hline
\end{tabular}

All dimensions of industry environment variable of MSME shows a loading factor value greater than 0.500 and composite reliability and average variance extracted values greater than the minimum, i.e.: 0.700 and 0.600 . The result determines that all dimensions of industry environment variable of MSME are valid and reliable.
The most important dimension is the intensity of industry competition with the greatest loading factor. However, this dimension shows achievement average value which is relatively low. Hence, this dimension is supposed to be the focus of attention to make improvement in industry environment of MSME.

Table 10: Validity and Reliability Analysis of Second Order Variable of Business Environment Variable

\begin{tabular}{|c|c|c|c|c|c|c|}
\hline \multicolumn{2}{|c|}{ Dimension } & Average & Loading Factor & R2 & Variance Error & t-Value \\
\hline External Environment & LE & 3.325 & 0.954 & 0.910 & 0.090 & 50.729 \\
\hline Industry Environment & LI & 3.506 & 0.887 & 0.787 & 0.213 & 24.103 \\
\hline
\end{tabular}

All dimensions in business environment variable of MSME possess a loading factor value greater than 0.500 ; and composite reliability and average variance extracted values also greater than the minimum values 0.700 and 0.600 . It shows that all dimensions of business environment variable of MSME are valid and reliable.
The most important dimension is the external environment with the greatest loading factor. However, this dimension shows achievement average value which is relatively low. Hence, this dimension is supposed to be the focus of attention to make improvement in the transient business environment of MSME.

Table 11: Validity and Reliability Analysis of Second Order Variable of Capability Variable

\begin{tabular}{|c|c|c|c|c|c|c|}
\hline Dimension & Average & Loading Factor & $\mathrm{R}^{2}$ & Variance Error & $\mathrm{t}$-Value \\
\hline Balance between stability and responsiveness & $\mathrm{K} 1$ & 3.554 & 0.831 & 0.691 & 0.309 & 18.387 \\
\hline Resources relocation & $\mathrm{K} 2$ & 3.384 & 0.832 & 0.692 & 0.308 & 21.281 \\
\hline Building innovation excellence & $\mathrm{K} 3$ & 3.486 & 0.901 & 0.812 & 0.188 & 34.270 \\
\hline Leadership pattern and company's mind set & $\mathrm{K} 4$ & 3.746 & 0.785 & 0.617 & 0.383 & 19.105 \\
\hline Composite Reliability & & \multicolumn{3}{|c|}{0.904} \\
\hline
\end{tabular}

All the dimensions in capability variable of MSME come with a loading factor greater than 0.500 ; and composite reliability and average variance extracted values also greater than the minimum, i.e.: 0.700 and 0.600 . The result defines that all the dimensions of capability variable of MSME are valid and reliable. The most important dimension is building innovation excellence, having the greatest loading factor. However, this dimension comes with achievement average value which is relatively low. Therefore, this dimension must become the focus of attention to make improvement in transient capability of MSME.

Table 12: Validity and Reliability Analysis of Second Order of Competitive Advantage Variable

\begin{tabular}{|c|c|c|c|c|c|c|}
\hline \multicolumn{2}{|c|}{ Dimension } & Average & Loading Factor & $\mathrm{R}^{2}$ & Variance Error & $\mathrm{t}$-Value \\
\hline Marketing function & $\mathrm{KB} 1$ & 3.458 & 0.810 & 0.656 & 0.344 & 16.457 \\
\hline Finance management function & $\mathrm{KB} 2$ & 2.905 & 0.838 & 0.703 & 0.297 & 18.065 \\
\hline Resources management function & $\mathrm{KB} 3$ & 2.893 & 0.845 & 0.714 & 0.286 \\
\hline Composite Reliability & & & 0.870 & 19.036 \\
\hline Average Variance Extracted & & & 0.691 \\
\hline
\end{tabular}


All the dimensions of competitive advantage variable of MSME indicate a loading factor value greater than 0.500 ; and composite reliability and average variance extracted values also greater than the minimum 0.700 and 0.600 . The result verifies that all the dimensions of competitive advantage variable of MSME are valid and reliable. The most important dimension is the dimension of resources management function, coming out with the greatest loading factor. However, this dimension comes with achievement average value which is relatively low. Therefore, this dimension is required to be the focus to make improvement in transient competitive advantage of MSME.

Table 13: Validity and Reliability Analysis of Second Order Dimension of Business Performance Variable

\begin{tabular}{|c|c|c|c|c|c|c|}
\hline \multicolumn{2}{|c|}{ Dimension } & Average & Loading Factor & $\mathrm{R}^{2}$ & Variance Error & $\mathrm{t}$-Value \\
\hline Financial perspective & KIN1 & 3.348 & 0.760 & 0.578 & 0.422 & 10.412 \\
\hline Customer perspective & KIN2 & 3.509 & 0.844 & 0.713 & 0.287 & 17.122 \\
\hline Business proses perspective & KIN3 & 3.476 & 0.867 & 0.751 & 0.249 & 23.171 \\
\hline Learning and growth perspective & KIN4 & 3.440 & 0.775 & 0.600 & 0.400 & 15.875 \\
\hline Composite Reliability & & \multicolumn{3}{|c|}{0.886} \\
\hline
\end{tabular}

All the dimensions of business performance variable of MSME have the loading factor value greater than 0.500; and also composite reliability and average variance extracted values greater than the minimum 0.700 and 0.600 . Such condition confirms that all the dimensions of business performance variable of MSME are valid and reliable. The most important dimension is the business process perspective, coming out with the greatest loading factor value. However, this dimension comes with achievement average value which is relatively low. Therefore, this dimension is required to be the focus to make improvement in transient competitive advantage of MSME

\subsubsection{Structural Model}

After the testing of the measurement model was conducted and concluded, it can be concluded that there were two indicators which were not valid. The following diagram shows the structural model analysis to answer the hypothesis of the research. The calculation of structural model has used R program with PLSPM package as shown in the following picture.

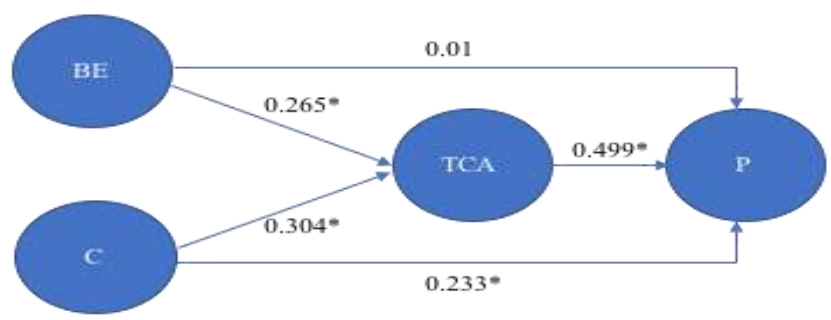

Fig. 2: Model of the Influence of Business Environment and Capability towards the Transient Competitive Advantage and the Implications for the Business Performance of MSME (Note: ${ }^{*}$ ) significant at the level of significance $5 \%$ )

\section{Hypothesis 1:}

Direct Influence of Business Environment and Capability Variables on the Transient Competitive Advantage

Table 14: Test Result of Significance on the Direct Influence of Business Environment and Capability Variable towards Transient Competitive Advantage

\begin{tabular}{|c|c|c|c|}
\hline Influence & Regression Coefficient & Standard Error & t-Value \\
\hline $\mathrm{LB} \rightarrow \mathrm{KB}$ & 0.265 & 0.121 & 2.192 \\
\hline $\mathrm{K} \rightarrow \mathrm{KB}$ & 0.304 & 0.169 & 1.798 \\
\hline \multicolumn{2}{|l}{} \\
Coefficient of determination $\mathrm{R}^{2}=0.240$ & \\
\hline
\end{tabular}

The analysis indicates that the direct influence of business environment variable towards the transient competitive advantage comes at 0.265 deviation standard with the $t$ calculated value 2.192. The value of $t$ calculated which is greater than the value of $t$ table is tested positive at the significance level 5\% (1.674) such indicates that there is a positive and significant influence of business environment variable towards the transient competitive advantage of MSME. Further, capability provides influence as much as 0.304 deviation standard towards competitive advantage. The influence of capability on competitive advantage is also significant with the value of $t$ calculated greater than the value of $t$ table. Determination coefficient of the direct influence of Business Environment and Capability variables towards the Transient Competitive Advantage 0.240 shows that $24.4 \%$ changes on Transient Competitive Advantage can be explained by Business Environment and Capability Variables.

\section{Hypothesis 2:}

Direct Influence of Business Environment, Capability, and Transient Competitive Advantage Variables on the Business Performance of MSME

Table 15: Result of Significance Test on the Direct Influence of Business Environment, Capability and Transient Competitive Advantage on the Business Performance of MSME

\begin{tabular}{|c|c|c|c|}
\hline Influence & Regression Coefficient & Error Standard & $\mathrm{t}$-Value \\
\hline $\mathrm{LB} \rightarrow \mathrm{KIN}$ & 0.011 & 0.134 & 0.081 \\
\hline $\mathrm{K} \rightarrow \mathrm{KIN}$ & 0.233 & 0.126 & 1.844 \\
\hline $\mathrm{KB} \rightarrow \mathrm{KIN}$ & 0.499 & 0.113 & 4.402 \\
\hline Determination Coefficient $\mathrm{R}^{2}=0.410$ & \multicolumn{3}{|l}{} \\
\hline
\end{tabular}

From the table, it can be figured out that the direct influence of business environment variable on business performance is 0.011 deviation standard with the value of $t$ calculated 0.081 . The value of $\mathrm{t}$ calculated than $\mathrm{t}$ table is tested positive at the significance level $5 \%$ (1.674). Hence, it shows that there is no significant influence from business environment variable towards the business performance. Further, capability comes with influence 0.233 deviation standard over the Business Performance. The effect of capability over the Business Performance is also significant with the value of $t$ calculated greater than the value of $t$ table. The variable that provides the greatest influence is the Competitive Advantage variable with an influence value 0.499 deviation standard with the value of $\mathrm{t}$ calculated 4.402 . The result confirms that changes on business performance is mostly influenced by the transient competitive advantage.

The determination coefficient of the direct influence of Business Environment, Capability, and Competitive Advantage variables towards Business Performance 0.410 defines that as much as $41 \%$ changes on Business Performance can be explained by Business Environment, Capability, and Transient Competitive Advantage variables.

\section{Hypothesis 3:}

Indirect Influence of Business Environment and Capability over the Business Performance of MSME through Transient Competitive Advantage

Table 16: The Result of Significance Test on Indirect Influence of Business Environment and Capability over the Business Performance of MSME through Transient Competitive Advantage

\begin{tabular}{|c|c|c|c|}
\hline Influence & Regression Coefficient & Standard Error & $\mathrm{t}$-Value \\
\hline $\mathrm{LB} \rightarrow \mathrm{KB} \rightarrow \mathrm{KIN}$ & 0.132 & 0.067 & 2.004 \\
\hline $\mathrm{K} \rightarrow \mathrm{KB} \rightarrow \mathrm{KIN}$ & 0.152 & 0.091 & 1.703 \\
\hline
\end{tabular}


The table shows that the influence of business environment variable on the business performance of MSME is not significant. However, with mediating competitive advantage variable, business environment variable contributes indirect influence on the business performance with the value of influence at 0.132 with the value of $t$ calculated 0.204 . The result describes that an increase in the influence of the business environment variable towards competitive advantage shall be able to boost the business performance. The same result is obtained for capability variable with indirect influence 0.152 with the value of $t$ calculated 1.703 . The value of $t$ calculated is also greater than the value of t table. Thus, it can be concluded that capability variable also contributes indirect influence on the business performance of MSME through transient competitive advantage at the level of significance $5 \%$.

\section{Conclusion}

The research found that business environment variable does not influence significantly on the business performance of MSME. However, this variable contributes indirect influence significantly greater than its direct influence. The result of the study shows that improvement in business environment will be able to boost the business performance if it is combined with improvement on the competitive advantage of MSME.

\section{Acknowledgement}

We thank to anonymous reviewers for their so-called insights.

\section{References}

[1] Klaus S (2016) The Global Competitiveness Report (2016-2017) World Economic Forum. http://www3.weforum.org/docs/GCR2016-

2017/05FullReport/TheGlobalCompetitivenessReport20162017_FINAL.pdf.

[2] The annual report of the minister of cooperatives and micro, small and medium enterprises (UMKM) (2016).

[3] The annual report of the minister of cooperatives and micro, small and medium enterprises (UMKM) (2017).

[4] Altschuller S, Gelb DS, Henry TF (2010) A Resource for Competitive Agility: An Analysis of Firm Performance During Industry Turbulence. Journal of International Technology and Information Management, 19, 39-59.

[5] Ansoff HI, McDonnell EJ (1990) Implanting Strategic Management. Prentice Hall.

[6] Eisenhardt KM (1989) Building theories from case study research Academy of Management Review, 14(4), 532-550.

[7] Hosseini SM, Sheikhi N (2012) An Empirical examination of competitive capability's contribution toward form performance. International Business Research, 5(5), 116-131.

[8] Indiatsy CM, Mwangi MS, Mandere EN, Bichanga JM, George GE (2014) The Application of Porter's Five Forces Model on Organization Performance: A Case of Cooperative Bank of Kenya Ltd. European Journal of Business and Management, 6(16), 75-85.

[9] Teece DJ (2007) Explicating Dynamic Capabilities: The Nature and Micro Foundations of (Sustainable) Enterprise Performance. Strategic Management Journal, 28(13), 1319-1350.

[10] Hill CWL, Jones GR (2013) Strategic Management: An Integrated Approach. South-Western.

[11] Porter ME (1989) How competitive forces shape strategy. In D Asch, C Bowman (Eds.), Readings in strategic management. London: Palgrave, pp. 133-143.

[12] Hunger JD \& Wheelen TL (2011) Essentials of Strategic Management. Prentice Hall.

[13] Porter ME (1980) Competitive Strategy. Free Press.

[14] McGrath RG (2013) The End of Competitive Advantage: How to keep your strategy moving as fast as your business. Harvard Business Review Press.

[15] Kaplan RS, Norton DP (2014) Strategy Maps. Harvard Business School Publishing

[16] Hair JF, Hult GTM, Ringle C, Sarstedt M (2016) A Primer on Partial Least Squares Structural Equation Modeling (PLS-SEM). Sage Publications. 